\title{
The influence of red deer space use on the distribution of Ixodes ricinus ticks in the landscape
}

\author{
Lars Qviller $^{1}$, Hildegunn Viljugrein ${ }^{1,2}$, Leif Egil Loe ${ }^{3}$, Erling L. Meisingset ${ }^{4}$ and Atle Mysterud ${ }^{*}$
}

\begin{abstract}
Background: Many wingless ectoparasites have a limited capacity for active movement and are therefore primarily dependent on hitchhiking on their hosts for transportation. The distribution of the tick Ixodes ricinus is expected to depend mainly on transportation by hosts and tick subsequent survival in areas where they drop off. In Europe, the most important hosts of adult female I. ricinus are cervids. The extensive space use of large hosts provides a much larger dispersal potential for I. ricinus than that of smaller mammalian hosts. We aim to determine the contribution of red deer (Cervus elaphus) space use on the spatial distribution of I. ricinus, after accounting for landscape factors.

Methods: We analysed the spatial distribution of I. ricinus with generalised mixed effects models (GLMMs) based on data from extensive field surveys of questing density in two coastal regions in Norway, from which home range data from 73 red deer with GPS collars were available. Red deer home ranges were derived using the kernel method to identify areas most frequently used by deer. We first fitted a baseline model with tick questing densities relative to landscape features that are likely to affect local climate conditions and hence, survival. We then added deer space use variables to the baseline model with only landscape variables to test whether areas more frequently used by red deer had higher questing tick densities.
\end{abstract}

Results: Questing I. ricinus density was predicted by several landscape features, such as elevation, distance to the fjord and topographic slope. In addition, we found that areas more heavily used within the red deer home ranges, correlated with higher questing tick densities. Increased effects of deer space use were additive to the landscape model, suggesting that correlations were more than just shared landscape preferences between deer and ticks.

Conclusions: Our results imply that the distribution of I. ricinus is controlled by a complex set of factors that include both local conditions related to landscape properties that affect survival and how the large host population redistributes ticks. In particular, we have provided evidence that the local distribution of large hosts, with their extensive space use, redistributes ticks at the local scale.

Keywords: Ixodes ricinus, Ticks, Parasite distribution, Red deer, Large hosts, Spatial distribution, Tick management, Risk maps, Species distribution modelling (SDM), Cervid home range

\footnotetext{
* Correspondence: atle.mysterud@ibv.uio.no

${ }^{1}$ Centre for Ecological and Evolutionary Synthesis (CEES), Department of

Biosciences, University of Oslo, P.O. Box 1066, Blindern NO-0316, Oslo,

Norway

Full list of author information is available at the end of the article
} 


\section{Background}

The spatial distribution of ectoparasites can usually be reduced to a function of how favourable the local conditions are to their survival, the parasite's own active locomotive abilities, and passive transportation by their hosts. Different groups of ectoparasites differ largely in these traits [1]. Winged insects such as mosquitoes have high auto-locomotive dispersal potential [1], and some ectoparasites such as deer keds (Lipoptena cervi) have winged stages that occur prior to settling on a host and shedding the wings [2]. However, ticks have a limited dispersal potential on their own. Their small size and lack of wings make them slow to intermediate self-dispersers, and their long distance dispersal therefore depends on host movement. One of the most common ectoparasites in Europe is the sheep tick Ixodes ricinus, which is known to transmit several zoonotic pathogens such as Borrelia burgdorferi (sensu lato) (s.l.), which causes Lyme disease [3], and the virus that causes tick-borne encephalitis [4, 5]. An understanding of the factors that affect tick distribution as a function of host space use is therefore important from a public health perspective.

Ixodes ricinus is a three-host, three-stage hard tick (Acari: Ixodidae) that attaches to hosts and engorges continuously for a few days during every life stage $[6,7]$. They spend off-host periods in the environment, either in climatically induced diapause, developmental diapause or questing for new hosts. Ixodes ricinus typically lives for 3-6 years [8], and the off-host period can last for many months [9]. The highest mortalities are thought to occur as a result of abiotic factors that are experienced in periods between attachment to hosts [10]. Ticks capacity for horizontal movement is limited to only a few centimetres during the most active season, and so limited horizontal movement is negligible at the landscape scale $[11,12]$. Host movement and space use are therefore likely important in the distribution of I. ricinus [1], but few detailed studies have been conducted to explore these patterns [13].

Tick larvae and nymphs use a wide range of vertebrate host sizes, including both birds and small mammals [9, 10]. In our study area in Norway, small mammals seem to play a key role in many of these host-tick relationships [14]. The space use of rodents is often limited to a few hundred square metres and up to possibly $5,000-6,000 \mathrm{~m}^{2}$ $[15,16]$. Adult females of $I$. ricinus can only engorge successfully on animals larger than a hare (Lepus spp.), and typically obtain their meal from a deer [17]. There are quite a few studies on the correlation between the density of ixodid ticks and the density of several deer species [18-20], but no study on the relationship between the distribution of $I$. ricinus and explicit measurements of deer space use based on GPS-collared animals. In Europe, roe deer (Capreolus capreolus) and red deer
(Cervus elaphus) are reproduction hosts for I. ricinus [21], and they are the most widely distributed deer species in Europe [22]. Red deer home ranges can extend over several square kilometres [23], and we may therefore expect deer to have a considerably greater potential to affect the local distribution of ticks than do small mammals, though this remains to be documented. The role of long-distance dispersal of especially larval ticks by birds is well established [24]. However, the role of space use of large mammalian hosts for I. ricinus distribution at local scales has rarely been assessed.

Here, we use an existing model describing how landscape features affect the spatial distribution of $I$. ricinus to explore whether the model can be improved by adding red deer space use parameters. We term this the red deer space use-tick distribution hypothesis, and we test this hypothesis by adding red deer space use parameters to the landscape model using tick abundance data from the corresponding home ranges of red deer in the spring prior to migration and the summer after migration. We test the following predictions: (i) I. ricinus abundances increase towards the more frequently used centre of red deer home ranges, and (ii) I. ricinus abundances decrease with larger seasonal home ranges of red deer because larger home ranges have less concentrated space use.

\section{Methods}

\section{Study area}

The data were collected in two areas on the west coast of Norway (Fig. 1). The first area is in the middle of Sogn \& Fjordane County, delimited by the fjords Sognefjorden in the south and Nordfjord in the north (study area SF). The climate is Atlantic with mild winters and cool summers. Meteorological 30-year averages (1961-1990) for this area are $2,270 \mathrm{~mm}$ of precipitation and a temperature of $6.0^{\circ} \mathrm{C}$ annually (http:// met.no; Norwegian meteorological station no. 57170). The second area lies in the northern parts of Møre \& Romsdal County and the western parts of Sør-Trøndelag County (study area MR). This area is delimited by the Tingvollfjorden fjord in the west and the Orkdal valley in the east. Meteorological 30-year averages for study area MR is an annual temperature of $5.6^{\circ} \mathrm{C}$ and 1,160 $\mathrm{mm}$ annual precipitation (http://met.no; Norwegian meteorological station no. 64550). The vegetation in both study areas lie within the boreonemoral vegetation zone [25]. The forests have natural stands of Scots pine (Pinus sylvestris), alder (Alnus incana) and birch (Betula spp.). There are also stands of Norway spruce (Picea abies) from extensive forest cultivation [26]. The terrain in both study areas is rugged with alpine formations. Summits and plateaus more than $1,000 \mathrm{~m}$ a.s.l. are common a few kilometres from the fjords. Red deer is the main deer species in the areas of SF and MR included here, though some areas have lower numbers of roe deer and moose 


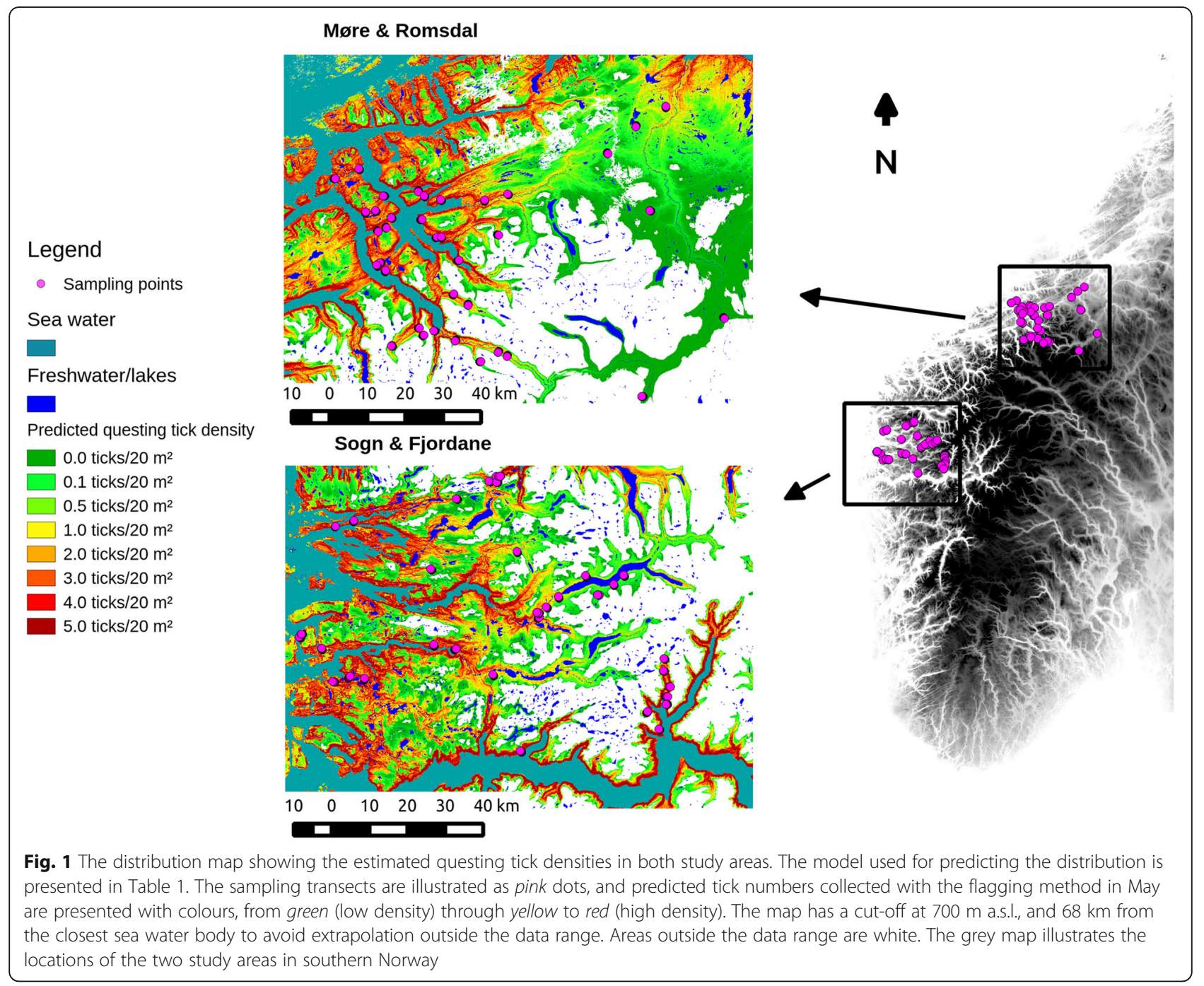

(Alces alces). There are no reindeer (Rangifer tarandus) in these areas, as reindeer in Norway are restricted to alpine habitat. Domestic sheep (Ovis aries) are common in the study area. They graze in spring and late autumn mainly on fenced infields, and graze mainly on alpine habitat outside reach of most of the tick population during the summer. Mountain hare (Lepus timidus) is present, but in low numbers. The main surveyed areas did not have cattle (Bos taurus) grazing apart from two transects. Red deer are therefore the main reproduction host to ticks in the study areas.

\section{Red deer GPS data and space use}

This study was based on GPS data from 73 adult (2 years or older) individuals of migratory and resident red deer, with 41 from Sogn \& Fjordane and 32 from Møre \& Romsdal County, Norway. Red deer were marked with GPS collars (Followit AB, Lindesberg, Sweden) [27-29]. The red deer were immobilised with darts at their winter feeding sites between 2005 and 2011 using a protocol approved by the Norwegian Animal Research Authority. Most collars registered the positions of the animals every hour, but some registered positions every second hour to prolong battery life. The duration of monitoring varied between a few months to 2 years. We used data only from the main tick questing period between May 1st and August 31st [30] in the present study. If there were adequate data for a particular deer for 2 years, we used the data from the year closest to the tick sampling period. Extreme outlying locations were considered to be GPS errors, and we removed them from our analyses according to standard protocols [31].

We calculated the space use within red deer home ranges using the kernel methods [32] in the R-package "adehabitat" [33]. Kernel isoclines and isopleths define areas that account for a specified proportion of an animal's total utilisation distribution. For example, the $50 \%$ kernel isocline encloses the smallest area (isopleth) the 
monitored individual is expected to inhabit $50 \%$ of the time, and a smaller kernel value means that the space use density is higher. We estimated 18 isopleths for each individual red deer, using percentages from 10 to $95 \%$ in $5 \%$ intervals (Fig. 2). Values outside the $95 \%$ isopleths were set to $100 \%$. The smoothing factor (h) used was the median of the $h$ values of all individuals, according to the reference method [32], and we examined the fit of kernel isopleths visually to validate the estimates. We divided the space use into seasonal home ranges, and kernel values were calculated separately for the spring and summer periods. The spring kernel values

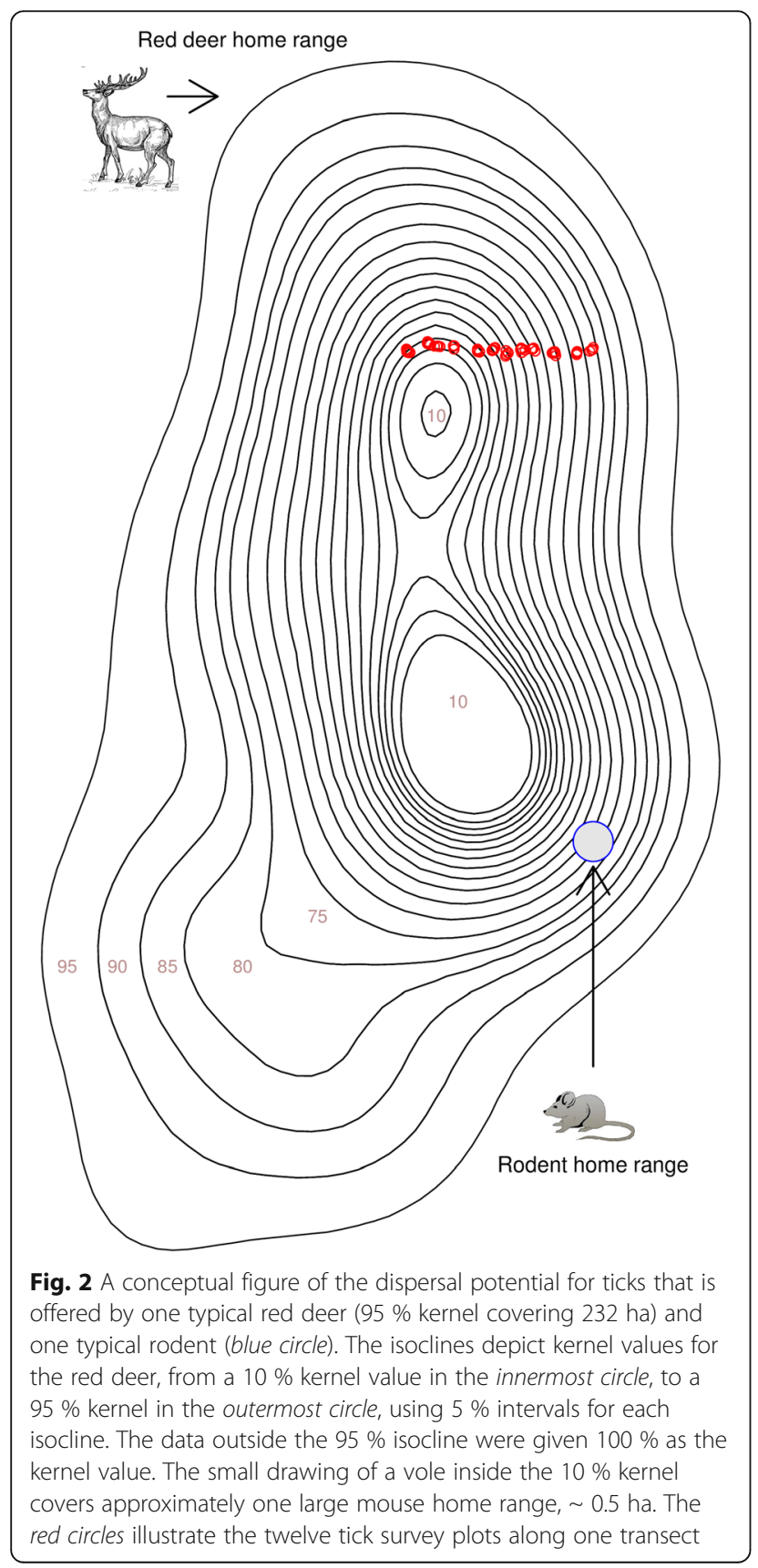

included GPS positions from May prior to migration for migratory individuals and for the entire month of May for resident red deer. The summer kernel values included the remainder of the summer after the spring migration event, ranging from June through August. The migration period was not included in the kernel estimates. The kernel isopleth (10-95\%) that each tick sampling plot (see below) falls within (termed "kernel"), as well as the home range size (defined as the area included within the $95 \%$ isocline), are used as predictor variables in the analyses.

\section{Sampling of questing ticks}

Ticks were sampled along 71 transects in May and August of the years 2009-2013 in Sogn \& Fjordane and in 2011-2013 in Møre \& Romsdal (resulting in one more year of data relative to [29]). Each transect consisted of twelve survey plots with randomised distances between them that were 20 to $50 \mathrm{~m}$ in length. The transects were established along the main elevational gradient. All transects were placed within or bordering the $95 \%$ kernel home ranges of the GPS-marked red deer. Several animals had overlapping home ranges, and all of the summer and winter home ranges of all 73 red deer were covered by these 71 transects. In Sogn \& Fjordane, we sampled 16 transects in the winter/resident home ranges and 15 transects in the summer home ranges, in addition to two transects that covered both resident and summer ranges, and one transect that covered both summer and winter home ranges (34 transects in total). In Møre \& Romsdal, we sampled 20 transects in the winter/resident home ranges and 17 in the summer ranges (37 transects in total).

Ticks were collected with the flagging method [34]. The sampling equipment was a white towel $(100 \times$ $50 \mathrm{~cm}$ ) made of cotton attached to the end of a rod as a flag, and sampling was conducted by dragging the towel over the vegetation so that questing ticks could attach. The towels were replaced if they became wet or dirty. UTM coordinates were registered using a handheld Garmin GPSmap 60CSx during every visit to the survey plots. Each of the survey plots covered approximately $20 \mathrm{~m}^{2}$, in a $10 \times 2 \mathrm{~m}$ wide belt. Ticks were counted and removed after every $2 \mathrm{~m}$. Tick numbers were divided into the number of nymphs, adult males and adult females for each survey plot. The tick counts for each plot are referred to as questing tick densities because the flagged area was equal in all plots. What we refer to as "tick questing density" is hence the number of adult and nymphal ticks in the $20 \mathrm{~m}^{2}$ survey plot. Tick questing density will reflect a combination of actual tick density as well as variation in tick activity. However, as we sample over longer time periods, we assume that 
variation caused by weather conditions influencing questing activity just adds noise to our data.

\section{Geographical covariates}

Terrain data were calculated from a $10 \times 10 \mathrm{~m}$ digital elevation raster model (DEM), retrieved from Norge Digitalt (DEM @ Kartverket; http://www.statkart.no/geonorge/norge-digitalt/). We used the DEM to extract a collection of geographical properties using the GRASS GIS software [35]. The "distance to fjord" variable was calculated as the Euclidean distance to the closest sea water body, while the topographical slope and the aspect of hillsides were calculated using generic functions included in the GRASS GIS software. The output of the aspect function is degrees of east, which increases in a counter-clockwise direction. Aspect was then recalculated to the degree of northern exposure using the sinus function to avoid problems with the circular nature of this covariate. The resulting variable is termed "northness", and ranges from -1 (southfacing) to 1 (northfacing). We also derived categories of habitat type from a land resource map provided by the Norwegian Institute of Bioeconomy Research, and the following classification was used: agricultural pastures, deciduous forests, coniferous forests, mixed forests, unclassified forests, marshes, and natural vegetation without forests. Elevation was recorded at each survey plot using GPS.

\section{Statistical analyses}

All statistical analyses were performed using $\mathrm{R}$ statistical software version 3.0.2 [36]. We analysed questing tick densities with the R package "glmmADMB" [37]. Parasite abundance data are often overdispersed, and it is therefore common to use a negative binomial probability distribution [38, 39]. Initial analyses confirmed that negative binomially distributed errors gave the best fit, while accounting for zero inflation did not improve the model fit. We included transect as a random intercept term to account for any spatial dependency in tick density. Nonlinear relationships were explored with generalised additive models using the " $m g c v$ " package in R [40]; nonlinear terms were included in the model selection procedure on the basis of this analysis. Variables were standardised (centred on the mean and divided by the standard deviation) to facilitate the comparison of effect sizes. Multicollinearity was checked with correlations and variance inflation factors as suggested by Zuur et al. [41]. It is common to separate tick instar stages in analyses of questing activity [42]. Adult ticks constitute $\sim 10 \%$ of the total number of ticks in these coastal areas, and previous investigations revealed no significant seasonal trends in instar compositions $[29,30]$. Tick instar stages were therefore pooled prior to the analyses.
We began by fitting an overall landscape model for tick distribution in May that covered the entire study area, using the following fixed effects: study area, slope, distance to fjord, elevation as a second degree polynomial, northness and vegetation categories; transect and year were included in the model as random effects. There was no strong collinearity between any of the covariates included in the model selection procedure. All correlation inflation factors were below 2 [41]. The model is similar, but not identical, to a previously published model built using a subset of the data [29]. Relative to the published model, we added extra covariates known to affect habitat selection by red deer to ensure that any added effects of deer space use was not a result of the absence of these covariates [43].

We aimed to evaluate whether questing tick densities depend on red deer space use in addition to the landscape parameters, either in May in the home ranges that were used by red deer during winter, or in August in the ranges they used during summer. We therefore refitted the landscape model for May using only the data from the winter and resident home ranges, and for August using data only from the red deer home ranges. We then added the red deer home range parameters as fixed effects: (i) Landscape model using the questing tick densities from May in the winter/resident home ranges as the response, and then adding the winter home range variables; (ii) Landscape model using the questing tick densities from August in the summer/resident home ranges as the response, and then adding home range variables for both the resident and summer ranges of migrants.

The number of years between the sampling of ticks and the registering of red deer movements were also added to the models. This was done to control for potential changes in red deer space use and demographics during the time between deer monitoring and the quantification of tick abundance.

\section{Cross-validation of the landscape model}

When fitting an overall landscape model for tick distribution in May, we used Bayesian information criterion (BIC) for model selection. The landscape model was evaluated using cross-validation. A reduced dataset (training data; $n=2718$ ) was used to fit a training model with the specifications from the selected landscape model and to predict the test data $(n=500 ; 250$ from each study area) that was not included. This procedure was repeated 400 times. Model consistency was then assessed based on the $R^{2}$-values from linear regressions between the predictions from the training model and the original landscape model. The $400 R^{2}$ values from this analysis were presented as the median, and $5 \%$ and $95 \%$ quantiles of these data. For illustrative purposes, 
we extrapolated a model in space and presented it as a "risk map" for the predicted questing tick density in the study area in May (Fig. 1).

\section{Replication of individuals relative to transects}

Several red deer had partly overlapping home ranges and were represented by one common transect, but most were not part of the same group and moved independently of one another. The analyses were therefore performed at the individual red deer level. Questing tick densities in May were analysed against the home range kernel values from 53 individual red deer, both migratory and resident, and these home ranges were represented by 35 of the transects in the winter/resident home range areas. Questing tick densities in August were analysed against the kernel values from resident and migratory deer in their summer/resident ranges, consisting of 70 individual red deer that were represented by 59 of the transects. This replication was handled statistically by the use of red deer identity as a random effect. However, the replication of landscape features introduces a bias towards transects with many deer individuals. This was especially a problem in the winter ranges where the overlap was more prevalent. This bias was removed using a bootstrap procedure with 400 repeated analyses. All transects that covered more than one red deer were assigned to one red deer individual at random in each of the repetitions, and estimates were calculated as the average over all 400 estimates.

This approach makes the use of likelihood-based model selection criteria more complicated. Home range is a property of the red deer identity, and it is therefore also highly correlated with the random effects. The inclusion of these parameters may therefore not improve the model likelihood, even though they explain a significant portion of the variation. Instead, the inclusion of these parameters may shift the variance explained from the random to fixed effects. The effects of the home range parameters are evaluated by whether they reduce the variance in the random effects and by their effect sizes and $P$-values.

\section{Results}

A total number of 24,146 ticks were collected; 15,026 in May and 9,120 in summer. In May, 95 \% kernel home ranges of red deer covered between 76 and 1,228 ha (median $=257$ ), while the summer ranges covered between 84 and 2,895 ha (median $=293$ ).

The baseline model with the landscape variables only included a positive effect of slope and a negative effect of northness (more ticks on the south face), elevation as a concave 2 nd degree polynomial with a peak tick abundance at $\sim 150 \mathrm{~m}$ a.s.l., and a negative effect of distance to fjord (Table 1). Pairwise comparisons showed that
Table 1 Parameter estimates and test statistics for the best model predicting the number of ticks caught in May with the flagging method between the years 2009 and 2013 along the west coast of Norway. Baseline is the study area in Sogn \& Fjordane County and the land resource category "agricultural pastures" (intercept). Møre \& Romsdal County is reported as the deviation from the baseline (Sogn \& Fjordane). All model estimates are derived from standardised covariates

\begin{tabular}{|c|c|c|c|c|}
\hline Parameter & Estimate & Standard error & Z & P \\
\hline Intercept & -0.12 & 0.37 & -0.33 & 0.73 \\
\hline Slope & 0.34 & 0.040 & 8.4 & $<0.001$ \\
\hline Northness & -0.22 & 0.054 & -4.2 & $<0.001$ \\
\hline Elevation & -0.28 & 0.094 & -3.0 & $<0.001$ \\
\hline Elevation $^{2}$ & -0.28 & 0.070 & -4.1 & 0.0029 \\
\hline Distance to fjord & -1.2 & 0.25 & -4.5 & $<0.001$ \\
\hline Coniferous forest & -0.032 & 0.18 & -0.18 & 0.86 \\
\hline Deciduous forest & 0.29 & 0.17 & 1.7 & 0.08 \\
\hline Mixed forest & 0.099 & 0.29 & 0.34 & 0.74 \\
\hline Unclassified forest & 0.92 & 0.28 & 3.3 & $<0.001$ \\
\hline Marshes & -1.4 & 0.41 & -3.4 & $<0.001$ \\
\hline Without forest & -0.47 & 0.29 & -1.7 & 0.095 \\
\hline Study area (MR vs SF) & 0.93 & 0.31 & 3.0 & 0.0030 \\
\hline
\end{tabular}

Land resource categories have the following factor levels in addition to the intercept: coniferous forest, deciduous forest, mixed forest, unclassified forest, marshes and natural vegetation without forests (without forest)

ticks tend to prefer forest coverage rather than marshes or areas without forest cover. The landscape model is shown as a map in Fig. 1, with a cut-off at $700 \mathrm{~m}$ a.s.l. and $68 \mathrm{~km}$ from the closest fjord to avoid extrapolation outside the data range. The model performed well when subjected to cross-validation, with a median $R^{2}$ of 0.994 (quantiles: $5 \%=0.960$ and $95 \%=0.998$ ).

The addition of red deer space use parameters from the winter/resident home ranges in May to the refitted landscape model with data from home ranges used in May resulted in a reduction in the random effect variances [variances: red deer identity $=0.88$, year $=0.26$ (baseline landscape only model); red deer identity = 0.73 , year $=0.10$ (adding deer space use)], in addition to significant $P$-values. There were no significant effects of home range parameters on the summer/resident ranges in August. As predicted, questing tick densities were negatively correlated with the home range kernel value and home range size in May, but the effect of home range size was not significant $(P=0.061$; Table 2, Fig. 3 ). These results indicate that increases in the amount of time spent in an area by a red deer increases the number of ticks. The tracking of deer with GPS and the survey for ticks was not done the same year. In addition, there was a negative correlation between tick abundance and the number of years between deer monitoring and tick sampling, i.e. there were fewer ticks when 
Table 2 Parameter estimates for the landscape model that also includes kernel estimates from red deer home ranges. The model predicts the numbers of ticks caught in May, representing winter and resident home ranges, with the flagging method between the years 2009 and 2013. Baseline is the study area in Sogn \& Fjordane County (intercept) and the land resource category "agricultural pastures". Møre \& Romsdal County is reported as the deviation from the baseline (Sogn \& Fjordane). Estimates are averaged over all 400 estimates from the bootstrap analysis

\begin{tabular}{lccll}
\hline Parameter & Estimate & Standard error & $Z$ & $P$ \\
\hline Intercept & 2.2 & 0.51 & 4.3 & $<0.001$ \\
Northness & -0.21 & 0.050 & -4.3 & $<0.001$ \\
Slope & 0.36 & 0.046 & 7.8 & $<0.001$ \\
Elevation & 0.015 & 0.076 & 0.20 & 0.73 \\
Elevation ${ }^{2}$ & -0.079 & 0.051 & -1.6 & 0.14 \\
Distance to fjord & -1.1 & 0.17 & -6.6 & $<0.001$ \\
Coniferous forest & 0.067 & 0.17 & 0.40 & 0.63 \\
Deciduous forest & 0.49 & 0.16 & 3.0 & 0.020 \\
Mixed forest & 0.53 & 0.35 & 1.5 & 0.15 \\
Unclassified forest & 1.1 & 0.27 & 3.9 & $<0.001$ \\
Marshes & -1.3 & 0.49 & -2.6 & 0.016 \\
Without forest & -0.043 & 0.26 & -0.17 & 0.66 \\
Kernel & -0.21 & 0.066 & -3.2 & 0.012 \\
Years between & -0.30 & 0.074 & -4.1 & $<0.001$ \\
Home range size & -0.15 & 0.072 & -2.1 & 0.062 \\
Study area (MR vs SF) & -0.50 & 0.45 & -1.1 & 0.27 \\
\hline
\end{tabular}

Land resource categories have the following factor levels in addition to the intercept: coniferous forest, deciduous forest, mixed forest, unclassified forest, marshes and natural vegetation without forests (without forest). Estimates are derived from standardised covariates. Note that this is a subset of data used in Table 1. Note also that high kernel values indicate that an area is used less frequently by red deer

there were more years between red deer monitoring and the tick survey.

\section{Discussion}

Here, we provide evidence that the density of questing $I$. ricinus ticks is higher in the core than in the periphery of individual red deer home ranges. The improved explanatory power of the addition of red deer space use metrics to a baseline landscape model indicates that the effect of red deer space use was a result of more than just shared landscape preferences of ticks and deer. This suggests that fine-scale variation in the space use of large hosts affects the distribution of ticks in this northern forest ecosystem.

Tick distributions are known to follow climatic gradients. The baseline landscape models include factors that correlate with the climatic conditions to avoid that these factors cause bias. That large hosts such as deer can also have an impact on the distribution of I. ricinus is an

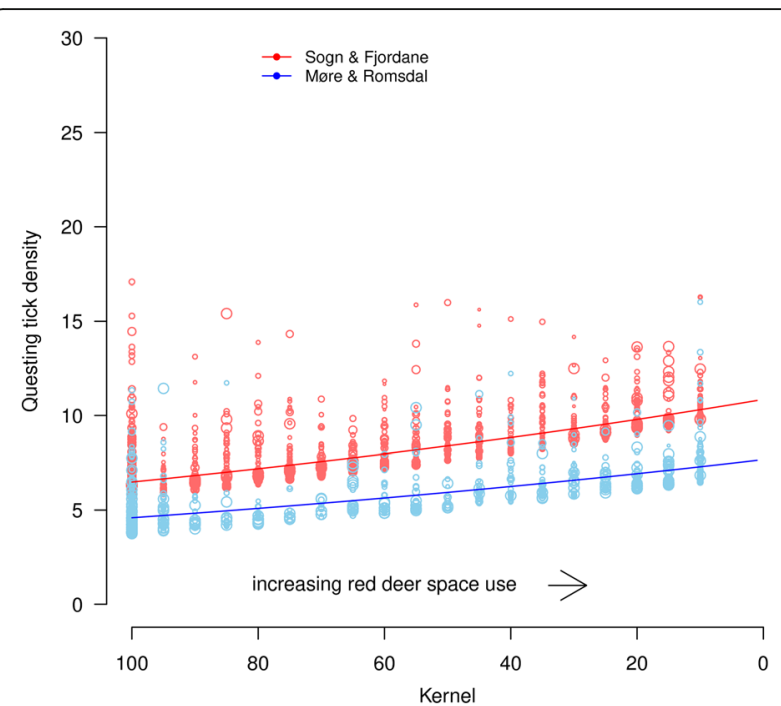

Fig. 3 The relationship between questing tick densities and the probability of red deer space use in both study areas. Note that kernel estimates are low in areas that are used more by deer, and we have therefore inverted the $x$-axis to present increasing space use more intuitively as we move to the right along this axis. The data points represent the residuals from the predicted values. The sizes of the data points are scaled relative to the home range sizes, and show that higher questing tick densities occur when home range sizes decrease

established concept $[17,44]$. It has been suggested that these large hosts may act as vehicles that distribute these parasites in the landscape [13]. We found that the individual home range kernel value (i.e. how much time the deer spent within a given area) and the time lag between red deer monitoring and tick sampling were significant predictors of questing tick density, but only in May. As predicted from the red deer space use-tick distribution hypothesis, the correlations between tick density and both home range kernel values were negative. This means that tick density increased with the amount of time a red deer spent in an area (Table 2, Fig. 3), thus supporting the hypothesis that red deer transport ticks in the landscape. The home range kernel value is scaled relative to an individual deer's space use and is therefore calculated independent of large scale deer densities. It may still act as a proxy for more general habitat selection of red deer in that area and is thus also a proxy for local deer density. The home range size of deer in general may decrease with increased densities (e.g. for roe deer [45]). The effect of home range size on tick abundance was negative, but marginally non-significant. The size of a home range reflects how concentrated the area is being used by red deer individuals, the local red deer population density and the overlap with the core home ranges of other unmarked individuals. In principle, such co-occurrence may also be due to a common preferred, but unmeasured habitat variable [46]. The negative effect 
of the time lag between deer monitoring and the tick sampling adds further evidence to an association between the GPS-marked red deer (and associated individuals) and tick distribution, as the landscape variables remain constant while the effect of an absent red deer gradually decreases away over time.

We found no association between red deer space use during summer and the tick density in August. There is great variation in questing activity throughout the active season [30]. Ticks in diapause and ticks engorging on hosts are not detected with the flagging method and are therefore difficult to estimate [10]. It is possible that the increased pick-up rate by hosts counteracts the effect of deer space use as the summer progresses, thus reducing the effect of red deer space use on the density of remaining questing ticks in August. Additionally, the social organisation of red deer changes from spring to summer. During spring, the red deer often remain in larger herds, so the space use of a particular GPS-marked individual may represent a large number of deer. During summer, red deer spread out and females live in small family groups of 2-3 individuals [47].

Rodents have very limited home range sizes compared to deer species (Fig. 2). Bank voles (Myodes glareolus), for example, typically use between a few hundred square metres and 0.5 ha $(0.2$ ha on average) $[15,16]$. One half hectare is the size of a circle with an approximately $40 \mathrm{~m}$ radius, which is an area comparable to that of a large garden. Such movements have little effect on the distribution of ticks at a larger scale [48]. In contrast, the red deer in the present study have a large dispersal potential for ticks, as they use large areas that range between 78 and 1,228 ha during May (Fig. 2). If a tick drops off its host and falls to the ground, it will likely remain within or near the same area until it is picked up again by a host. Hence, the effect of deer space use, and kernel estimates in particular, both reflect the limited movements of ticks and the space use by abundant smaller hosts. Birds also have the potential to transport ticks over large distances $[24,49,50]$. A study of the biogeography of Lyme disease spirochetes in Europe have demonstrated that the genetic structures of different Borrelia genospecies were linked to the movement capabilities of their vertebrate hosts [51]. Borrelia afzelii, which specialises on rodents, had a highly genetically structured distribution, while B. garinii, which specialises on avian hosts, showed evidence of greater genetic mixing [51]. However, the genospecies composition of $B$. burgdorferi (s.l.) in Norway is dominated by the small mammal specialist $B$. afzelii, providing evidence that the most common hosts for immature ticks are rodents [52]. It is therefore likely that the genetic structure of ticks follows red deer movement patterns in this northern ecosystem.

\section{Conclusion}

Ticks have a limited capacity for locomotion, and their distribution in the landscape is therefore assumed to follow the movements of their hosts. We have provided evidence that the variation in space use by red deer correlates with the local distribution of ticks on the western coast of Norway. Our study highlights that the local distribution of large hosts, with their extensive space use, redistributes ticks at the local scale.

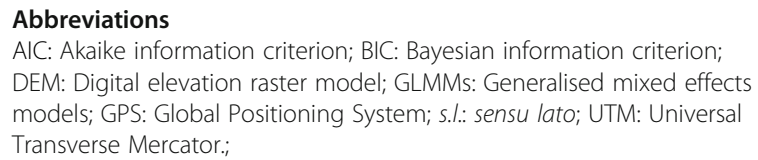
DEM: Digital elevation raster model; GLMMs: Generalised mixed effects models; GPS: Global Positioning System; s.I: sensu lato; UTM: Universal Transverse Mercator.;

\section{Acknowledgements}

We are grateful to Nina Risnes Olsen, Vetle Stigum, Kim Magnus Bærum, and Marius Bless for their valuable help with the field work. We would also like to thank Stefan Blumentrath for his help with the digital elevation model and valuable GIS advice, and two anonymous referees for helpful comments to a previous draft. Wiley Editing Service provided linguistic editing.

\section{Funding}

This study was funded by the Research Council of Norway and the Norwegian Environmental Agency through the projects TickDeer (project number 203786) and \#EcoTick (project number 254694).

\section{Availability of data and material}

Host movement data are available at http://bioweb07.bioforsk.no/hjortegis/ hovedframe.php?hoyde $=830 \&$ bredde $=1470$.

\section{Authors' contributions}

$L Q, H V, A M, E M$ and $L E L$ designed the study. $L Q, H V$, LEL and $A M$ designed and LQ carried out the data analysis. LQ and AM drafted the manuscript. All authors read and approved the final version of the manuscript.

\section{Competing interests}

The authors declare that they have no competing interests.

\section{Consent for publication}

Not applicable.

Ethics approval and consent to participate

Not applicable.

\section{Author details}

${ }^{1}$ Centre for Ecological and Evolutionary Synthesis (CEES), Department of Biosciences, University of Oslo, P.O. Box 1066, Blindern NO-0316, Oslo, Norway. ${ }^{2}$ Norwegian Veterinary Institute, P.O. Box 750, Sentrum NO-0106, Oslo, Norway. ${ }^{3}$ Department of Ecology and Natural Resource Management, Norwegian University of Life Science, P.O. Box 5003NO-1432 Aas, Norway. ${ }^{4}$ Department of Forestry and Forestry resources, Norwegian Institute of Bioeconomy Research, NO-6630 Tingvoll, Norway.

Received: 7 June 2016 Accepted: 2 October 2016

Published online: 13 October 2016

\section{References}

1. Randolph SE. Ticks are not insects: consequences of contrasting vector biology for transmission potential. Parasitol Today. 1998;14:186-92.

2. Härkönen L, Härkönen S, Kaitala A, Kaunisto S, Kortet R, Laaksonen S, et al. Predicting range expansion of an ectoparasite - the effect of spring and summer temperatures on deer ked Lipoptena cervi (Diptera: Hippoboscidae) performance along a latitudinal gradient. Ecography. 2010;33:906-12.

3. Piesman J, Gern L. Lyme borreliosis in Europe and North America. Parasitology. 2004;129(Suppl):S191-220. 
4. Randolph SE, Rogers DJ. Fragile transmission cycles of tick-borne encephalitis virus may be disrupted by predicted climate change. Proc $\mathrm{R}$ Soc Ser B. 2000;267:1741-4

5. Randolph SE, Green RM, Peacey MF, Rogers DJ. Seasonal synchrony: the key to tick-borne encephalitis foci identified by satellite data. Parasitology. 2000;121:15-23.

6. Medlock JM, Hansford KM, Bormane A, Derdakova M, Estrada-Peña A, George J-C, et al. Driving forces for changes in geographical distribution of Ixodes ricinus ticks in Europe. Parasit Vectors. 2013;6:1.

7. Apanaskevich DA, Oliver Jr JH. Life cycles and natural history of ticks. In: Sonenshine DE, Roe RM, editors. Biology of Ticks, vol. 1. New York: Oxford University Press; 2014. p. 59-73.

8. Sonenshine DE, Roe RM. Biology of Ticks, Volume 1. 2nd ed. New York: Oxford University Press; 2014.

9. Randolph SE, Green RM, Hoodless AN, Peacey MF. An empirical quantitative framework for the seasonal population dynamics of the tick Ixodes ricinus. Int J Parasitol. 2002:32:979-89.

10. Randolph SE. Ecology of non-nidicolous ticks. In: Sonenshine DE, Roe RM, editors. Biology of ticks, Vol. 2. 2nd ed. New York: Oxford University Press; 2014. p. 3-39.

11. Milne A. The ecology of the sheep tick, Ixodes ricinus L. Parasitology. 1950;40:14-34.

12. Crooks E, Randolph SE. Walking by Ixodes ricinus ticks: intrinsic and extrinsic factors determine the attraction of moisture or host odour. J Exp Biol. 2006; 209:2138-42.

13. Ruiz-Fons F, Gilbert $L$. The role of deer as vehicles to move ticks, Ixodes ricinus, between contrasting habitats. Int J Parasitol. 2010;40:1013-20.

14. Mysterud A, Byrkjeland R, Qviller L, Viljugrein H. The generalist tick Ixodes ricinus and the specialist tick Ixodes trianguliceps on shrews and rodents in a northern forest ecosystem - a role of body size even among small hosts. Parasit Vectors. 2015;8:639.

15. Kikkawa J. Movement, activity and distribution of the small rodents Clethrionomys glareolus and Apodemus sylvaticus in woodland. J Anim Ecol. 1964:33:259-99.

16. Kozakiewicz M, Chołuj A, Kozakiewicz A. Long-distance movements of individuals in a free-living bank vole population: an important element of male breeding strategy. Acta Theriol. 2007;52:339-48.

17. Gray JS. The ecology of ticks transmitting Lyme borreliosis. Exp Appl Acarol. 1998:22:249-58

18. Ostfeld RS, Canham CD, Oggenfuss K, Winchcombe RJ, Keesing F. Climate, deer, rodents, and acorns as determinants of variation in Lyme-disease risk. PLoS Biol. 2006:4:e145.

19. Jaenson TGT, Jaenson DGE, Eisen L, Petersson E, Lindgren E. Changes in the geographical distribution and abundance of the tick Ixodes ricinus during the past 30 years in Sweden. Parasit Vectors. 2012;5:8

20. Gilbert L, Maffey GL, Ramsay SL, Hester AJ. The effect of deer management on the abundance of Ixodes ricinus in Scotland. Ecol Appl. 2012;22:658-67.

21. Vor T, Kiffner C, Hagedorn P, Niedrig M, Rühe F. Tick burden on European roe deer (Capreolus capreolus). Exp Appl Acarol. 2010;51:405-17.

22. Apollonio M, Andersen R, Putman R. European ungulates and their management in the 21st century. Cambridge: Cambridge University Press; 2010.

23. Rivrud IM, Loe LE, Mysterud A. How does local weather predict red deer home range size at different temporal scales? J Anim Ecol. 2010;79:1280-95.

24. Hasle G, Bjune G, Edvardsen E, Jakobsen C, Linnehol B, Røer JE, et al. Transport of ticks by migratory passerine birds to Norway. J Parasitol. 2009; 95:1342-51.

25. Abrahamsen J, Jacobsen NK, Kalliola R, Dahl E, Wilborg L, Pahlsson L. Naturgeografisk regioninndeling av Norden. Nord Utredningsserie B. 1977; 34:1-135.

26. Mysterud A, Langvatn R, Yoccoz NG, Stenseth NC. Large-scale habitat variability, delayed density effects and red deer populations in Norway. J Anim Ecol. 2002;71:569-80

27. Mysterud A, Loe LE, Zimmermann B, Bischof R, Veiberg V, Meisingset E. Partial migration in expanding red deer populations at northern latitudes a role for density dependence? Oikos. 2011;120:1817-25.

28. Bischof R, Loe LE, Meisingset EL, Zimmermann B, Van Moorter B, Mysterud A. A migratory ungulate in the pursuit of spring: jumping or surfing the green wave? Am Nat. 2012;180:407-24.

29. Qviller L, Risnes-Olsen N, Bærum KM, Meisingset EL, Loe LE, Ytrehus B, et al. Landscape level variation in tick abundance relative to seasonal migration in red deer. PLoS One. 2013;8:10.
30. Qviller L, Grøva L, Viljugrein H, Klingen I, Mysterud A. Temporal pattern of questing tick Ixodes ricinus density at differing elevations in the coastal region of western Norway. Parasit Vectors. 2014;7:179.

31. Bjørneraas K, Moorter B, Rolandsen CM, Herfindal I. Screening global positioning system location data for errors using animal movement characteristics. J Wildl Manage. 2010;74:1361-6.

32. Worton BJ. Kernel methods for estimating the utilization distribution in home-range studies. Ecology. 1989;70:164.

33. Calenge $\mathrm{C}$. The package adehabitat for the $\mathrm{R}$ software: a tool for the analysis of space and habitat use by animals. Ecol Modell. 2006;197:516-9.

34. Vassallo M, Pichon B, Cabaret J, Figureau C, Perez-Eid C. Methodology for sampling questing nymphs of Ixodes ricinus (Acari: Ixodidae), the principal vector of Lyme disease in Europe. J Med Entomol. 2000;37:335-9.

35. GRASS Development Team. Geographic Resources Analysis Support System (GRASS GIS) Software [Internet]. USA: Open Source Geospatial Foundation; 2013.

36. R Development Core Team. R: A language and environment for statistical computing [Internet]. R Found. Stat. Comput. Vienna Austria. Vienna: R Foundation for Statistical Computing; 2013.

37. Skaug H, Fournier D, Nielsen A, Magnusson A, Bolker B. glmmADMB: Generalized Linear Mixed Models Using AD Model Builder [Internet]. 2011.

38. Zuur AF, leno EN, Walker N, Saveliev AA, Smith GM. Mixed Effects Models and Extensions in Ecology with R [Internet]. New York: Springer; 2009.

39. James MC, Bowman AS, Forbes KJ, Lewis F, McLeod JE, Gilbert L. Environmental determinants of Ixodes ricinus ticks and the incidence of Borrelia burgdorferi sensu lato, the agent of Lyme borreliosis, in Scotland. Parasitology. 2013;140:237-46.

40. Wood SN. Fast stable restricted maximum likelihood and marginal likelihood estimation of semiparametric generalized linear models. J R Stat Soc 2011:73:3-36

41. Zuur AF, leno EN, Walker N, Saveliev AA, Smith GM. Limitations of linear regression applied on ecological data. In: Zuur AF, leno EN, Walker N, Saveliev AA, Smith GM, editors. Mixed effects models and Extensions in ecology with R. New York: Springer; 2009. p. 11-33.

42. Cadenas FM, Rais O, Jouda F, Douet V, Humair P, Moret J, et al. Phenology of Ixodes ricinus and infection with Borrelia burgdorferi sensu lato along a north- and south-facing altitudinal gradient on Chaumont Mountain, Switzerland. J Med Entomol. 2007:44:683-93.

43. Godvik IMR, Loe LE, Vik JO, Veiberg V, Langvatn R, Mysterud A. Temporal scales, trade-offs, and functional responses in red deer habitat selection. Ecology. 2009;90:699-710.

44. Gilbert L. Altitudinal patterns of tick and host abundance: a potential role for climate change in regulating tick-borne diseases? Oecologia. 2010;162:217-25.

45. Kjellander P, Hewison AJM, Liberg O, Angibault J-M, Bideau E, Cargnelutti B. Experimental evidence for density-dependence of home-range size in roe deer (Capreolus capreolus L.): a comparison of two long-term studies. Oecologia. 2004;139:478-85.

46. Van Moorter B, Visscher D, Herfindal I, Basille M, Mysterud A. Inferring behavioural mechanisms in habitat selection studies getting the nullhypothesis right for functional and familiarity responses. Ecography. 2013;36: 323-30.

47. Bonenfant C, Loe LE, Mysterud A, Langvatn R, Stenseth NC, Gaillard J-M, et al. Multiple causes of sexual segregation in European red deer: enlightenments from varying breeding phenology at high and low latitude. Proc R Soc Lond Ser B. 2004;271:883-92.

48. Perkins SE, Cattadori IM, Tagliapietra V, Rizzoli AP, Hudson PJ. Localized deer absence leads to tick amplification. Ecology. 2006;87:1981-6.

49. Hasle G, Leinaas HP, Røed KH, Øines $\varnothing$. Transport of Babesia venatoruminfected Ixodes ricinus to Norway by northward migrating passerine birds. Acta Vet Scand. 2011:53:41.

50. Hasle G, Bjune GA, Midthjell L, Røed KH, Leinaas HP. Transport of Ixodes ricinus infected with Borrelia species to Norway by northward-migrating passerine birds. Ticks Tick Borne Dis. 2011;2:37-43.

51. Vollmer SA, Bormane A, Dinnis RE, Seelig F, Dobson ADM, Aanensen DM, et al. Host migration impacts on the phylogeography of Lyme borreliosis spirochaete species in Europe. Environ Microbiol. 2011;13:184-92.

52. Paulauskas A, Ambrasiene D, Radzijevskaja J, Rosef O, Turcinaviciene J. Diversity in prevalence and genospecies of Borrelia burgdorferi sensu lato in Ixodes ricinus ticks and rodents in Lithuania and Norway. Int J Med Microbiol. 2008;298:180-7. 